Research Article

\title{
Risk stratification and outcome in haematemsis patients in emergency room in Suez Canal university hospital, Ismailia, Egypt
}

\author{
Monira Taha ${ }^{1}$, Sameh Saad ${ }^{1}$, Adel Hamed Elbaih ${ }^{1} *$, Hosam Mohamad ${ }^{1}$, Gouda Ellabban $^{2}$
}

${ }_{1}^{1}$ Department of Emergency, Faculty of Medicine, Suez Canal University, Ismailia, Egypt
${ }^{2}$ Department of of General Surgery, Faculty of Medicine, Suez Canal University, Ismailia, Egypt

Received: 20 March 2016

Accepted: 10 May 2016

\section{*Correspondence:}

Dr. Adel Hamed Elbaih,

E-mail: elbaihzico@yahoo.com

Copyright: () the author(s), publisher and licensee Medip Academy. This is an open-access article distributed under the terms of the Creative Commons Attribution Non-Commercial License, which permits unrestricted non-commercial use, distribution, and reproduction in any medium, provided the original work is properly cited.

\section{ABSTRACT}

Background: Identify risk factors for upper gastrointestinal bleeding and establish the scoring system in order to divide patients into the high and low-risk group. The objective of this study was to risk stratification for haematemesis patients to get rapid evaluation and best management to improve outcome.

Methods: A descriptive cross-sectional study in emergency department at Suez Canal university hospital, 270 patients were included in this study.

Results: Patients were followed up until discharged or admitted to inpatient or in the hepatic care unit, had been divided into 2 groups (high and low risk groups). The low-risk group included 95 patients (35.2\%) while The high risk group included 175 patients $(64.8 \%) .28$ patients $(16 \%)$ from 175 patients with high risk had been died in the hospital, 8 patients from 39 patients in the ICU and 20 patients from 136 patients from the inpatient.

Conclusions: A new risk score system that could add value to discriminate high risk patients, this score had the cutoff value of 5 with high sensitivity, high specificity $72 \%, 86 \%$ respectively and AUC $40 \%$.

Keywords: Risk stratification, Outcome, Haematosis

\section{INTRODUCTION}

Acute upper gastrointestinal bleeding (or haematemsis) is a common major medical emergency; Initial triage and assessment are generic with emphasis on identifying the sick patient with life threatening haemodynamic compromise and initiating appropriate resuscitation. Certain clinical features associated with GI bleeding have been studied in attempts to identify patients at increased risk of morbidity and death. ${ }^{1}$

In Egypt, the commonest cause of upper GIT bleeding is bleeding oesophageal varices due to hepatic cirrhosis bilharzial or hepatitis c, bleeding oesophageal varices is the most common cause of upper GIT bleeding $(51.6 \%){ }^{2}$
Haematemesis is vomiting of blood from the upper gastrointestinal tract or occasionally after swallowing blood from a source in the nasopharynx. Bright red haematemesis usually implies active haemorrhage from the oesophagus, stomach or duodenum. This can lead to circulatory collapse and constitutes a major medical emergency Coffee-ground vomits refer to the vomiting of black material which assumed to be blood. ${ }^{3}$

Patients presenting with haematemesis have a higher mortality than those presenting with melena alone. ${ }^{3}$

\section{Risk factors associated with poor outcome}

There is a lack of good quality studies on the initial assessment of patients with acute upper GI bleeding. ${ }^{5}$ 
Limited evidence is available from cohort and case series which identify risk factors associated with poor outcome (variously defined) but usually without formal scoring. ${ }^{6}$

The following factors are associated with a poor outcome, defined in terms of severity of bleed, uncontrolled bleeding, rebreeding, need for intervention and mortality. These factors should be taken into account when determining the need for admission or suitability for discharge: the study aims to risk stratification for haematemesis patients to get rapid evaluation and best management to improve outcome.

\section{METHODS}

It is a descriptive cross-sectional study. Study conducted at emergency department at Suez Canal university hospital. All patients attended with haematosis within 24 hour after the attack.

\section{Inclusion criteria}

All patients attended with haematosis in both sex in all age group above two year within 24 hour after the attack.

\section{Exclusion criteria}

All patients attended with haematemsis within 24 hour after the attack below age two year because no facilities to do endoscopy for this age

The sample size will be calculated using the following equation.

$$
\mathrm{N}=(\mathrm{Z} \alpha / / \Delta)^{2} \mathrm{P}(1-\mathrm{P})
$$

Where,

P: The expected prevalence of haematemsis patients in emergency room $=20 \%$

$\mathrm{Z} \propto 2$ : A percentile of standard normal distribution $=1.96$.

$\Delta:$ The width of the confidence interval $=5 \%$.

Sample size $=246$ patients

By adding $10 \%$ drop out, Sample size will be 270 patients.

The population attending to the emergency department at Suez Canal University hospital will be divided depending on history, physical examination, initial evaluation and risk factors $(($ age + signs of shock + haemoglobin + urea level + onset of bleeding $=$ other comorbidities $)$ into 2 groups: high risk group and low risk group by the score system below.

\section{Patient outcome}

Improved, admitted, died or transferred.
Patient with score (5 or less) low risk group which will discharge while other patient in high risk group (8-12) will be admitted in the ward or in the hepatic care unit.

Table 1: Risk factors of patients with score

\begin{tabular}{|c|c|c|}
\hline Score & Parameter & Risk factor \\
\hline \multirow[t]{2}{*}{ Age ( years) } & $18-50$ & 1 \\
\hline & $\begin{array}{l}\text { Less than } 18 \text { and } \\
\text { more than } 50\end{array}$ & 2 \\
\hline \multirow[t]{2}{*}{ BP and pulse } & Normal & 1 \\
\hline & Shocked & 2 \\
\hline \multirow{2}{*}{$\begin{array}{l}\text { Time of } \\
\text { presentation }\end{array}$} & $1-2$ (hours) & 1 \\
\hline & More than 2 hours & 2 \\
\hline \multirow{2}{*}{$\begin{array}{l}\text { Haemoglobin } \\
(\mathrm{gm} / \mathrm{dl})\end{array}$} & More than 10 & 1 \\
\hline & Less than 10 & 2 \\
\hline \multirow[t]{2}{*}{ Urea (mg/dl) } & $16-30$ & 1 \\
\hline & More than 30 & 2 \\
\hline \multirow{6}{*}{$\begin{array}{l}\text { Other } \\
\text { co-morbidities }\end{array}$} & Nil & 0 \\
\hline & Melena & 1 \\
\hline & Liver disease & 1 \\
\hline & Cardiac & 1 \\
\hline & Renal & 1 \\
\hline & Other & 1 \\
\hline
\end{tabular}

\section{RESULTS}

The mean age in the low risk group was 41.07 years, $93.68 \%$ of them were $\leq 50$ years, and $6.32 \%$ was $>50$ years, while in the high risk group the mean age was 50 years, $60 \%$ of them was $\leq 50$ years, and $40 \%$ was $>50$ years. According to gender distribution in both groups, $63.16 \%, 42.84 \%$ were males and $36.84 \%, 57.14 \%$ were females in the low and high risk groups respectively (Table 2).

Table 2: Age and sex distribution among studied patients.

\begin{tabular}{|c|c|c|c|c|}
\hline & & $\begin{array}{l}\text { Low risk } \\
\text { group } \\
(\mathrm{n}=95)\end{array}$ & $\begin{array}{l}\text { High risk } \\
\text { group } \\
(n=175)\end{array}$ & $\begin{array}{l}\text { p- } \\
\text { value }\end{array}$ \\
\hline \multirow{4}{*}{ Age } & $\leq 50$ years & $89 \quad 93.68 \%$ & $105 \quad 60 \%$ & \multirow{2}{*}{$0.001 *$} \\
\hline & $>50$ years & $6 \quad 6.32 \%$ & $70 \quad 40 \%$ & \\
\hline & Mean \pm SD & $41.07 \pm 7.39$ & $49.15 \pm 8.86$ & \multirow{2}{*}{$0.001 *$} \\
\hline & Range & $4-56$ & $2-64$ & \\
\hline \multirow{2}{*}{ Sex } & Male & $60 \quad 63.16 \%$ & $75 \quad 42.86 \%$ & \multirow{2}{*}{$0.001 *$} \\
\hline & Female & $35 \quad 36.84 \%$ & $57.14 \%$ & \\
\hline
\end{tabular}

* Statistically significant difference (p-value < 0.05$)$.

The homodynamic state between both study groups, the mean heart rates were 72.26, 100.1 BPM in the low and high risk groups with statistically significant difference $(\mathrm{p}<0.001)$, while in terms of mean SBP were 117.84 , $98.63 \mathrm{mmHg}$ in the low and high risk groups with statistically significant difference $(\mathrm{p}<0.001)$, and in terms of mean DBP were $71.58,58.29 \mathrm{mmHg}$ in the low and 
high risk groups with statistically significant difference also $(\mathrm{p}<0.001)($ Table 3, 4).

In the present study, we revealed significant increase of urea in the high risk group in comparison with the low risk group, $52.01 \mathrm{mg} / \mathrm{dl}, 24.1 \mathrm{mg} / \mathrm{dl}$ respectively, with statistically significance $(\mathrm{p}<0.001)$.while, the hemoglobin level was significantly decreased in the high risk group in comparison with the low risk group, $8.4 \mathrm{gm} / \mathrm{dl}, 13.2 \mathrm{gm} / \mathrm{dl}$ respectively, with statistically significance $(\mathrm{p}<0.001)$ (Table 4).
Table 3: Vital signs among studied patients.

\begin{tabular}{|c|c|c|c|c|}
\hline & & $\begin{array}{l}\text { Low risk } \\
\text { group } \\
(\mathbf{n}=95)\end{array}$ & $\begin{array}{l}\text { High risk } \\
\text { group } \\
(\mathrm{n}=175)\end{array}$ & p-valus \\
\hline \multirow{2}{*}{ HR } & Mean \pm SD & $72.26 \pm 10.09$ & $100.14 \pm 12.72$ & \multirow{2}{*}{$0.001 *$} \\
\hline & Range & $63-134$ & $70-140$ & \\
\hline \multirow{2}{*}{ SBP } & Mean \pm SD & $117.84 \pm 8.33$ & $98.63 \pm 11.07$ & \multirow{2}{*}{$0.001 *$} \\
\hline & Range & $100-140$ & $70-140$ & \\
\hline \multirow{2}{*}{ DBP } & Mean \pm SD & $71.58 \pm 6.77$ & $58.29 \pm 9.03$ & \multirow{2}{*}{$0.001 *$} \\
\hline & Range & $60-90$ & $30-90$ & \\
\hline
\end{tabular}

* Statistically significant difference (p-value $<0.05)$.

Table 4: Comparison between clinical and laboratory factors of the studied groups.

\begin{tabular}{|c|c|c|c|c|c|c|c|c|}
\hline \multirow{3}{*}{ Sex } & \multirow{3}{*}{$\begin{array}{l}\text { Male } \\
\text { Female }\end{array}$} & \multicolumn{2}{|c|}{$\begin{array}{l}\text { ICU admission } \\
(\mathbf{n}=39)\end{array}$} & \multicolumn{2}{|c|}{$\begin{array}{l}\text { Inpatient admission } \\
(\mathrm{n}=136)\end{array}$} & \multicolumn{2}{|c|}{ Discharged (n=95) } & \multirow{3}{*}{$\begin{array}{l}\text { p-value } \\
0.001 *\end{array}$} \\
\hline & & 22 & $56.41 \%$ & 53 & $38.97 \% \#$ & 60 & $63.16 \%$ & \\
\hline & & 17 & $43.59 \%$ & 83 & $61.03 \%$ & 35 & $36.84 \%$ & \\
\hline \multirow{2}{*}{ Age } & $\leq 50$ years & 15 & $38.46 \% \#$ & 90 & $66.18 \% \#$ & 89 & $93.68 \%$ & \multirow{2}{*}{$0.001 *$} \\
\hline & $>50$ years & 24 & $61.54 \%$ & 46 & $33.82 \%$ & 6 & $6.32 \%$ & \\
\hline \multirow{2}{*}{ HR } & $\leq 81$ & 0 & $0 \% \#$ & 14 & $10.29 \% \#$ & 92 & $96.84 \%$ & \multirow{2}{*}{$0.001 *$} \\
\hline & $>81$ & 39 & $100 \%$ & 122 & $89.71 \%$ & 3 & $3.16 \%$ & \\
\hline \multirow{2}{*}{ SBP } & $>105$ & 1 & $2.56 \% \#$ & 37 & $27.21 \% \#$ & 94 & $98.95 \%$ & \multirow{2}{*}{$0.001 *$} \\
\hline & $\leq 105$ & 38 & $97.44 \%$ & 99 & $72.79 \%$ & 1 & $1.05 \%$ & \\
\hline \multirow{2}{*}{ DBP } & $>60$ & 1 & $2.56 \% \#$ & 42 & $30.88 \% \#$ & 83 & $87.37 \%$ & \multirow{2}{*}{$0.001 *$} \\
\hline & $\leq 60$ & 38 & $97.44 \%$ & 94 & $69.12 \%$ & 12 & $12.63 \%$ & \\
\hline Urea & Mean \pm SD & \multicolumn{2}{|c|}{$59.69 \pm 4.21$} & \multicolumn{2}{|c|}{$49.87 \pm 6.03 \#$} & \multicolumn{2}{|c|}{$24.16 \pm 3.11 \#$} & $0.001 *$ \\
\hline Hb & Mean \pm SD & \multicolumn{2}{|c|}{$6.7-11.1$} & \multicolumn{2}{|c|}{$6.7-11.1 \mathrm{~m}$} & \multicolumn{2}{|c|}{$11.1-14.1$} & $0.001 *$ \\
\hline
\end{tabular}

* Statistically significant difference (p-value < 0.05); NS: no statistically significant difference.

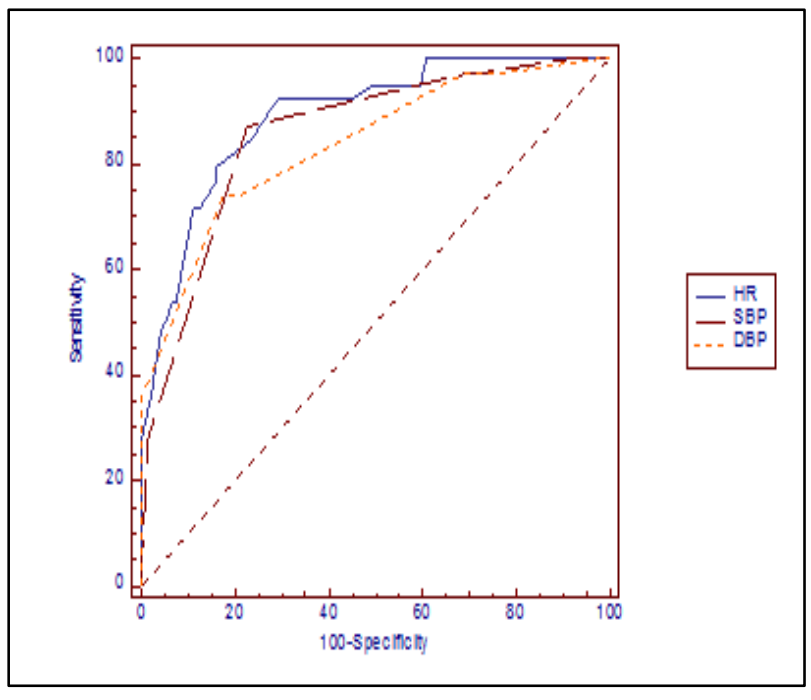

Figure 1: ROC curves of vital signs for prediction of ICU admission among high risk group.

From our study we revealed the criteria of ICU admission which was heart rate with best cutoff value $>105$ and (AUC $=89 \%$, sensitivity $80 \%$ and specificity $84 \%$ ), SBP with best cutoff value $\leq 90$ and $(\mathrm{AUC}=86 \%$, sensitivity
$87 \%$ and specificity $77 \%$ ), and DBP with best cutoff value $\leq 50$ and $(\mathrm{AUC}=84 \%$, sensitivity $74 \%$ and specificity 82\%) (Figure 1 and Table 5).

Table 5: Vital signs for prediction of ICU admission among high risk group.

\begin{tabular}{|c|c|c|c|c|c|c|}
\hline Parameter & $\begin{array}{l}\text { Bets } \\
\text { cut } \\
\text { off } \\
\text { value }\end{array}$ & $\begin{array}{l}\mathbf{A} \\
\mathbf{U} \\
\mathbf{C}\end{array}$ & sensitivity & Specificity & $\begin{array}{l}\mathbf{P} \\
\mathbf{P} \\
\mathbf{V}\end{array}$ & $\begin{array}{l}\mathbf{N} \\
\mathbf{P} \\
\mathbf{V}\end{array}$ \\
\hline HR & $>105$ & $89 \%$ & $80 \%$ & $84 \%$ & $59 \%$ & $93 \%$ \\
\hline SBP & $\leq 90$ & $86 \%$ & $87 \%$ & $77 \%$ & $52 \%$ & $96 \%$ \\
\hline DBP & $\leq 50$ & $84 \%$ & $74 \%$ & $82 \%$ & $55 \%$ & $92 \%$ \\
\hline
\end{tabular}

Table 6: Means of risk score and GBS among both study group.

\begin{tabular}{|lllll|}
\hline \multirow{2}{*}{$\begin{array}{l}\text { Risk } \\
\text { score }\end{array}$} & Mean \pm SD & $\begin{array}{l}\text { Low risk } \\
\text { group }\end{array}$ & $\begin{array}{l}\text { High } \\
\text { risk } \\
\text { group }\end{array}$ & $\begin{array}{l}\text { p- } \\
\text { value }\end{array}$ \\
\cline { 2 - 4 } Gange & $5-10$ & $8.6 \pm 1.7$ & \multirow{2}{*}{$0.0001 *$} \\
GBS & Mean \pm SD & $1.8 \pm 0.99$ & $13.8 \pm 2.03$ & \multirow{2}{*}{$0.0001 *$} \\
\cline { 2 - 4 } & Range & $0-4$ & $10-18$ & \\
\hline
\end{tabular}


In our study, the GBS was used with mean scores were $1.8,13.8$ in the low and high risk groups respectively and the difference between the two groups was statistically significant $(\mathrm{p}<0.001)$ but in our study mean scores were $6.1,8.6$ in the low and high risk groups respectively and the difference between the two groups was statistically significant $(\mathrm{p}<0.001)$ (Table 6).

Table 7: Outcome among studied patients.

\begin{tabular}{|c|c|c|c|c|c|}
\hline Outcome & & $\begin{array}{l}\text { risk } \\
\text { p } \\
5)\end{array}$ & $\begin{array}{l}\text { Higl } \\
\text { grol } \\
(\mathbf{n}=1\end{array}$ & $\begin{array}{l}\text { risk } \\
\text { 5) }\end{array}$ & p-value \\
\hline $\begin{array}{l}\text { ICU } \\
\text { admission }\end{array}$ & 0 & $0 \%$ & 39 & $22.29 \%$ & \multirow{3}{*}{$0.001 *$} \\
\hline $\begin{array}{l}\text { Inpatient } \\
\text { ward }\end{array}$ & 0 & $0 \%$ & 136 & $77.71 \%$ & \\
\hline Discharged & 95 & $100 \%$ & 0 & $0 \%$ & \\
\hline
\end{tabular}

* Statistically significant difference (p-value $<0.05$ ).

In our study outcome among 2 groups of the studied patients $77.71 \%$ (136) patients of the high risk groups were admitted to inpatient ward and $22.29 \%$ (39) patients admitted to ICU and (95)patients in low risk group discharged (Table 7).

\section{DISCUSSION}

Cases of gastrointestinal system bleeding represent a group of diseases that commonly leads to presentation to emergency departments of hospitals. Therefore, the evaluation of these patients is critical. GIS bleeding is a clinical problem with high mortality and diagnostic and therapeutic costs, and requires frequent hospitalization and intensive care. Rarely, it leads to difficulties in the diagnosis and differential diagnosis and may require a multidisciplinary study. ${ }^{11,12}$

Upper gastrointestinal (UGI) system bleeding, which accounts for $85 \%$ of all gastrointestinal bleeding cases and originates from the proximity of the treitz ligament, represents an important clinical and economic problem. While the incidence of UGI system bleeding is 50$172 / 100,000$, its mortality is approximately $11-14 \%$. The patients present to the ED due to clinical manifestations of varying grades. However, the majority of the patients do not have indications for emergent endoscope intervention, blood transfusion or hospitalization. ${ }^{13}$

In the patients who present to the ED with UGI system bleeding, the risk determination, location of the therapeutic endoscope, and the medical and surgical therapeutic indications remain conflicting, and therefore, there is no consensus concerning the approach to be adopted in these patients. In addition, although endoscope has an important place in the evaluation of these patients, centers with all-time accessibility to endoscope are limited in our country. Therefore, the patients at risk should be differentiated using a simple scoring system, without a need for endoscope.
Various scoring systems are used to classify the high-risk patients and distinguish the low-risk patients. Among these, the most commonly used scoring systems are Glasgow Blatchford Scoring (GBS) and Rockall scoring systems. In contrast to the Rockall scoring system, the GBS system provides a scoring based only on clinical and laboratory findings, without the use of endoscope data. $^{14}$

Various scoring systems are used to classify the high-risk patients and distinguish the low-risk patients. Among these, the most commonly used scoring systems are Glasgow Blatchford scoring (GBS) and Rockall scoring systems. In contrast to the Rockall Scoring system, the GBS system provides a scoring based only on clinical and laboratory findings, without the use of endoscope data. $^{14,15}$

The present study was aiming to make risk stratification for hematemesis patient to get rapid evaluation in order to receive better management and effective treatment to improve outcome.

This study included all patients attended with haematemsis in both sex of all age group above 1.5 year within 24 hour after the attack. A total of 270 patients attended to the emergency department at Suez Canal University hospital had been divided into 2 groups (high and low risk groups). The high risk group included 175 patients $(64.8 \%)$, while the low risk group included 95 patients $(35.2 \%)$

In the present study, the mean age in the low risk group was 41.07 years, $93.6 \%$ of them were $\leq 50$ years, and $6.4 \%$ was $>50$ years, while in the high risk group the mean age was 49.1 years, $60 \%$ of them was $\leq 50$ years, and $40 \%$ was $>50$ years. According to gender distribution in both groups, $63.1 \%, 42.8 \%$ were males and $36.9 \%$, $57.2 \%$ were females in the low and high risk groups respectively. In the study by Özlem KÖKSAL, The mean age was $57.76 \pm 15.46$ years. Of the patients, $30.6 \%$ were females and $69.4 \%$ were males. Given, the distribution of the subjects according to their age groups, $51.9 \%$ of the patients were $<60$ years old, $41.3 \%$ were $60-79$ years old and $6.9 \%$ were $\geq 80$ years old. ${ }^{16}$ While in the study by Rocke L, fifty four patients presented to the ED with UGIH. Thirty three $(61 \%)$ were males. The mean age was 49 years (range 16-91) (90). In the study by Terweec CB, 951 patients were included, with a median age of 71 years (range 2-100), of whom $25 \%$ were older than 80 years, and $60 \%$ were men. ${ }^{16}$

In our study, the GBS was used with mean scores were $1.8,13.8$ in the low and high risk groups respectively and the difference between the two groups was statistically significant $(p<0.001)$. These results were in consistent with Özlem KÖKSAL, who found in his research that the mean GBS score of the subjects hospitalized and referred was $10.81 \pm 3.48$, the mean GBS score of the subjects discharged was $6.70 \pm 3.9$, and the difference between the 
two groups was statistically significant $(\mathrm{p}<0.001)$ the difference between the two groups was statistically significant $(\mathrm{p}<0.001) .{ }^{16,17}$

In the present study, according to the homodynamic between both study groups, the mean heart rates were 72.2, 100.1 BPM in the low and high risk groups with statistically significant difference $(p<0.001)$, while in terms of mean SBP were $117.8,98.6 \mathrm{mmHg}$ in the low and high risk groups with statistically significant difference $(p<0.001)$, and in terms of mean DBP were $71.5,58.2 \mathrm{mmHg}$ in the low and high risk groups with statistically significant difference also $(\mathrm{p}<0.001)$. This was in agreement with Özlem KÖKSAL, who found in his research a significant difference was found between the subjects with a systolic blood pressure (SBP) $\geq 100$ $\mathrm{mmHg}$ and those with a SBP $<100 \mathrm{mmHg}$ in terms of mean GBS scores $(\mathrm{p}<0.001)$. Similarly, a significant difference was found between the subjects with a pulse rate $(P R) \geq 100 /$ min and the subjects with a $P R<100 /$ min in terms of mean GBS scores $(\mathrm{p}<0.001){ }^{18}$

In the present study, the haemoglobin level was significantly decreased in the high risk group in comparison with the low risk group, $8.4 \mathrm{gm} / \mathrm{dl}, 13.2 \mathrm{gm} / \mathrm{dl}$ respectively, with statistically significance $(p<0.001)$. This was in agreement with Corley DA, who had done univariate analysis that identified 17 distinct variables associated $(\mathrm{p}<0.05)$ with an adverse outcome. A stepwise logistic regression identified five variables as independent predictors ( $\mathrm{p}<0.05$ ) of an adverse outcome: an initial hematocrit $<30 \%$, initial systolic blood pressure $<100 \mathrm{~mm} \mathrm{Hg}$, red blood in the nasogastric lavage, history of cirrhosis or ascites on examination, and a history of vomiting red blood (93). Where Patumanond J, revealed decreased haemoglobin $<10 \mathrm{~g} / \mathrm{dL}(\mathrm{OR}=13.82,95 \% \mathrm{CI}=$ 9.40 to $20.33, \mathrm{P}<0.001)$, systolic blood pressure $<100$ $\mathrm{mmHg}(\mathrm{OR}=11.01,95 \% \mathrm{CI}=7.41$ to $16.36, \mathrm{P}<0.001)$ in the patients with severe UGIH. ${ }^{17,18}$

Also In the present study, we revealed significant increase of urea in the high risk group in comparison with the low risk group, $52.01 \mathrm{mg} / \mathrm{dl}, 24.1 \mathrm{mg} / \mathrm{dl}$ respectively, with statistically significance $(\mathrm{p}<0.001)$. This was inconsistent with Patumanond $\mathrm{J}$ who found blood urea nitrogen $\geq 35 \mathrm{mmol} / \mathrm{L}(\mathrm{OR}=1.73,95 \% \mathrm{CI}=1.25$ to $2.40, \mathrm{P}=0.001)$ in the severe bleeding patients. ${ }^{19}$

According to the results of our research, $77.1 \%$ of the high risk patients had one co morbid disease in comparison with the low risk patients with statistically significance $(p<0.001)$. And this is the same with Patumanond $\mathrm{J}$ who found in his research the presence of hepatic failure $(\mathrm{OR}=5.50,95 \% \mathrm{CI}=1.14$ to26.64, $\mathrm{P}=$ $0.037)$, and presence of cirrhosis $(\mathrm{OR}=2.03,95 \% \mathrm{CI}=$ 1.32 to $3.11, \mathrm{P}=0.001)$ in the patients with severe UGIH. ${ }^{19}$

In our study we found that all patients of low risk group (95) stay in emergency room from 12-36 hours to be investigated and resuscitated then discharged to home and 75 patients had been referred to GIT outpatient clinic to follow up .while patients of high risk group (175) admitted to inpatient or ICU stay in emergency room for 6-24 hours to be investigated and resuscitated.

Also in our study we found (16) patients died after admission to the hospital, (8) patients $=20.3 \%$ from 39 patients admitted to ICU and (20) patients $=14.7 \%$ from 136 patients admitted to inpatient, totally (5.7\%) from 175 patients of the high risk group. In the study by ÖzlemKÖKSAL, who found 2patients $=0.55 \%$ died from 384 patients in his study. ${ }^{16,19}$

Also in our study we found that there was statistically significant difference between the patients who were admitted to inpatients ward and admitted to ICU according to multivariable which were age ,HR, SBP,DBP, and urea level (p-value $<0.05$ ), and no significance had been found related to sex ( $\mathrm{p}$-value $=$ $0.05)$.

By doing regression analysis about the factors influencing admission to ICU in the patients of high risk, it was found that, HR and DBP significantly affect admission, in contrast to age and SBP which was found not influencing admission.

From our study we revealed the criteria of admission which was heart rate with best cut off value $>81$ and (AUC $=97 \%$, sensitivity 92\% and specificity 97\%), SBP with best cut off value $\leq 105$ and $(\mathrm{AUC}=92 \%$, sensitivity $78 \%$ and specificity 99\%), and DBP with best cut off value $\leq 60$ and (AUC $=88 \%$, sensitivity $75 \%$ and specificity $87 \%$ ).

Finally from our research we developed new risk score that could add value to discriminate high risk patients, this score had cut off value of 5 with high sensitivity, high specificity $72 \%, 86 \%$ respectively and AUC $40 \%$. There is a lack of good quality studies on the initial assessment of patients with acute upper GI bleeding. ${ }^{5}$

Limited evidence is available from cohort and case series which identify risk factors associated with poor outcome (variously defined) but usually without formal scoring. ${ }^{6}$

So the following factors are associated with a poor outcome, defined in terms of severity of bleed, uncontrolled bleeding, rebreeding, need for intervention and mortality. These factors should be taken into account when determining the need for admission or suitability for discharge:

- $\quad$ Age - mortality due to haematemesis increases with age across all age groups. ${ }^{2,6,7}$

- Co morbidity - the absence of significant co morbidity is associated with low mortality Rate Even one co morbidity almost doubles mortality and the presence of cardiac failure, chronic renal failure, 
diabetes mellitus or malignancy significantly worsens prognosis. ${ }^{7,8}$

- Liver disease - cirrhosis is associated with a doubling of mortality and much higher risk of interventions such as endoscope haemostasis or transfusion. ${ }^{9}$

- Initial shock (hypotension and tachycardia) is associated with increased mortality.

- Continued bleeding after admission is associated with high risk of increased mortality.

- Haematemesis - the presence of initial haematemesis (first attack) doubles mortality. ${ }^{3,8}$

\section{CONCLUSION}

UGIB is a common emergency disease, potentially lifethreatening condition that requires rapid assessment of clinical presentation, rapid resuscitative measures, and appropriate medical triage the patients into low and high risk groups and this scoring system was choose because it's easy and simple investigations needed with upper GIT bleeding in emergency department in Suez Canal University hospital in order to decrease mortality and morbidity 270 patients were included in this study. Patients were followed up until discharged or admitted to inpatient or in the hepatic care unit, had been divided into 2 groups (high and low risk groups). The low risk group included 95 patients $(35.2 \%)$, while the high risk group included 175 patients $(64.8 \%)$.

Funding: No funding sources

Conflict of interest: None declared

Ethical approval: The study was approved by the institutional ethics committee

\section{REFERENCES}

1. UK comparative audit of upper gastrointestinal bleeding and the use of blood. London: British Society of Gastroenterology; 2007. Available at http://www.bsg.org.uk/pdf_word_docs/blood_audit_ report_07.pdf. Accessed on 19 August 2008.

2. Elwakil R, Reda M, Abdelhakam S, Ghoraba D, Ibrahim W. Department of tropical medicine, faculty of medicine, Ain Shams University, Cairo 11566, Egypt. The Egyptian Society of Parasitological. 2013;41(2):455-67.

3. Blatchford O, Davidson L, Murray W, Blatchford M, Pell J. Acute upper gastrointestinal haemorrhage in west of Scotland: case ascertainment study. BMJ. 1997;315(7107):510-4.

4. Pongprasobchai S, Nimitvilai S, Chasawat J, Manatsathit S. Upper gastrointestinal bleeding aetiology score for predicting variceal and nonvariceal bleeding. World J Gastroenterology. 2009;15(9):1099-104.

5. Rockall T, Logan R, Devlin H, Northfield $\mathrm{T}$. Incidence of and mortality from acute upper gastrointestinal haemorrhage in the United Kingdom. Steering committee and members of the national audit of acute upper gastrointestinal haemorrhage. BMJ. 1995;311(6999):222-6.

6. Klebl F, Bregenzer N, Schofer L, Tamme W, Langgartner J, Scholmerich J, et al. Comparison of inpatient and outpatient upper gastrointestinal haemorrhage. Int J Colorectal Dis. 2005;20(4):36875.

7. Zimmerman J, Siguencia J, Tsvang E, Beeri R, Arnon R. Predictors of mortality in patients admitted to hospital for acute upper gastrointestinal hemorrhage. Scand J Gastroenterol. 1995;30(4):32731.

8. Cameron E, Pratap JN, Sims TJ, Inman S, Boyd D, Ward M, et al. Three-year prospective validation of a pre-endoscopic risk stratification in patients with acute upper-gastrointestinal haemorrhage. Eur $\mathrm{J}$ Gastroenterol Hepatol. 2002;14(5):497-501.

9. Lecleire S, Di Fiore F, Merle V, Herve S, Duhamel C, Rudelli A, et al. Acute upper gastrointestinal bleeding in patients with liver cirrhosis and in noncirrhotic patients: epidemiology and predictive factors of mortality in a prospective multicenter population-based study. J Clin Gastroenterol. 2005;39(4):321-7.

10. Wilcox C, Alexander L, Cotsonis G. A prospective characterization of upper gastrointestinal hemorrhage presenting with hematochezia. Am J Gastroenterol. 1997;92(2):231-5.

11. Longstreth F. Epidemiology of hospitalization for acute upper gastrointestinal bleeding: a populationbased study. Am J Gastroenterol. 1995;90:206-10.

12. Stanley J, Ashley D, Dalton R. Outpatient management of patients with low-risk uppergastrointestinal haemorrhage: multicentre validation and prospective eva-luation. Lancet. 2009;373:42-7.

13. Atkinson J, Hurlstone P. Usefulness of prognostic indi-ces in upper gastrointestinal bleeding. Best Pract Res Clin Gastroenterol. 2008;22:233-42.

14. Rockall A, Logan F, Devlin B, Northfield C. Incidence of and mortality from acute upper gastrointestinal haemorrhage in the United Kingdom. Steering Committee and members of the National Audit of Acute Upper Gastroin-testinal Haemorrhage. BMJ. 1995;311:222-6.

15. Courtney AE, Mitchell RMS, Rocke L, Johnston BT. Proposed risk stratification in upper gastrointestinal haemorrhage: is hospitalisation essential? Emerg Med J. 2004:21;39-40.

16. Özeren OKG, Özdem $\prec$ R F, Aydin EAS, Ayyildiz T. Prospective validation of the Glasgow Blatchford scoring system in patients with upper gastrointestinal bleeding in the emergency department. Turk J Gastroenterol. 2012;23(5):44855.

17. Vreeburga EM, Terweec CB, Snelb P, Rauwsa EAJ, Bartelsmana JFWM, vdMeulenc JHP, et al. Validation of the Rockall risk scoring system in upper gastrointestinal bleeding. Gut. 1999;44:331-5.

18. Corley DA, Stefan AM, Wolf M, Cook EF, Lee TH. Early indicators of prognosis in upper 
gastrointestinal hemorrhage. American Journal of Gastroenterology. 1998;93:336-40.

19. Chaikitamnuaychoka R, Patumanondb J. Clinical risk characteristics of upper gastrointestinal hemorrhage severity: a multivariable risk analysis. Gastroenterology Research. 2012;5(4):149-55.

Cite this article as: Taha M, Saad S, Elbaih AH, Mohamad H, Ellabban G. Risk stratification and outcome in haematemsis patients in emergency room in Suez Canal university hospital, Ismailia, Egypt. Int Surg J 2016;3:1249-55. 